\title{
Peningkatan Atensi pada Anak ADHD dengan Teknik Self Instruction
}

\author{
Fransisca Anindya Mariesta Prabawati, Niken Nurmei Ditasari \\ Fakultas Psikologi Universitas Timika; Jl. C. Heatubun No. 09, Timika, 081392992989 \\ e-mail: *1anindyaprabawati@gmail.com,2nikennurmei@gmail.com, \\ 3Psikologiuniversitastimika@gmaiil.com
}

\begin{abstract}
The aim of this study is to analyze the impact of self instruction method on attention improvement. Hypothesis of this study is self instruction method can increase attention of ADHD children.the subjects in this study are children which have been diagnosed with ADHD withage of 12 years old. Three behavior are observed, they are keep attention to the teacher, follow the teacher expression, and do the task until done according to teacher asking without leaving the chair. ABA design was used as study's design. Statistical analysis in the study was done using t-test method. Based on statistical result it was found that to $t_{0}(5,143)>t_{\text {tab }}(2,145)$ which can be concluded that treatment with self instruction method was significantly increase the attention of ADHD children.
\end{abstract}

Keywords: $A D H D$ children, inatenttion, self instruction

Abstrak. Tujuan penelitian ini adalah untuk melihat dampak metode self instruction dalam meningkatkan pemusatan perhatian. Hipotesis yang diajukan adalah metode self instruction dapat meningkatkan pemusatan perhatian pada anak ADHD. Subyek penelitian adalah anak yang didiagnosis ADHD usia 12 tahun. Perilaku yang diamati antara lain memperhatika npenjelasan guru, mengikuti ekspresi wajah guru, dan mengerjakan tugas sesaui perintah guru hingga selesa itanpa meninggalkan tempat duduk. Metode penelitian yang digunakan adalah ABA desain. Penghitungan analisis statistik menggunakan uji t. Hasil analisis statistika didapatkan angka $t_{0}(5,143) t_{t a b}(2,145)$. Berdasarkan hasil uji t maka hipotesis diterima.Hal tersebut dapat diartikan bahwa metode self inctruction dapat meningkatkan pemusatan perhatian pada anak ADHD.

Kata kunci: Anak ADHD, gangguanpemustanperhatian, self instruction 


\section{Pendahuluan}

Anak ADHD memiliki tiga gejala utama. Gejala-gejala tersebut antara lain gangguan pemusatan perhatian, hiperaktivitas, dan impulsivitas. Di setiap gejala terdapat beberapa kriteria untuk diperhatikan dalam penegakan diagnostik. Gejala-gejala ini ditunjukkan pada perilaku di rumah, di sekolah, dan di tempat umum (DSM V, 2003). Anak dapat didiagnosis ADHD pada saat ketiga gejala tersbeut muncul secara konsisten di tiga tempat yang telah disebut serta hasil dari tes psikologi yang diberikan.

Gangguan pemusatan perhatian merupakan salah satu gejala dari anak yang didiagnosis Attention Deficit Hyperactivity Disorder (ADHD). Gangguan pemusatan perhatian adalah kesulitan anak untuk mempertahankan perhatiannya (Paternotte dan Buitelaar, 2010). Anakanak ADHD mempunyai kesulitan memusatkan perhatiannya pada tugas tertentu. Kesulitan mempertahankan perhatian tersebut disebabkan karena adanya rangsangan dari luar yang sulit untuk didorong menjauh dari kesadarannya (Paternotte dan Buitelaar, 2010).

Berdasarkan DSM V (2003) gangguan pemusatan perhatian pada anak ADHD yang dapat diamati antara lain tidak tepat waktu dalam pelaksaan tugas, cepat beralih perhatian, dan tidak bisa konsentrasi. Selain gangguan pemusatan perhatian anak ADHD juga identik dengan perilaku impulsif. Impulsivitas yang ditunjukkan yakni kurang kontrol diri, tidak mampu menunggu giliran, dan bicara sebelum gilirannya. Gangguan pemusatan perhatian dan impulsivitas ini ditambah dengan perilaku hiperaktivitas yang ditunjukkan dengan sangat banyak gerak dan goyang-goyang, selalu on the go, dan tidak bisa berhenti bicara. Fokus penelitian kali ini adalah gangguan pemusatan perhatian pada anak ADHD.

Pemusatan perhatian dapat diukur menggunakan waktu atau durasi yakni seberapa lama anak dapat memusatkan perhatian (Schacter dan Millman, 1981). Durasi pemusatan perhatian berkembang seiring dengan perkembangan usia anak. Anak-anak usia 2 tahun akan dapat memusatkan perhatian selama 7 menit, 9 menit pada anak usia 3 tahun, 12 menit untuk anak usia 4 tahun, dan 14 menit untuk anak usia 5 tahun. Maka anak yang memiliki usia lebih dari 5 tahun seharusnya dapat memusatkan perhatian lebih dari 14 menit (Schacter dan Millman, 1981).

Menurut Ayres (2005) gangguan pemusatan perhatian dapat menjadi masalah yang utama di sekolah. Pada saat anak tidak dapat menghindar dari kebisingan dan cahaya serta kebingungan melihat akivitas orang yang berbeda-beda maka anak ini berpotensi mengalami gangguan pemusatan perhatian. Anak ADHD mempunyai kesulitan untuk mendorong rangsangan-rangsangan menjauh dari dirinya. Hal tersebut menyebabkan anak ADHD membutuhkan energi agar dapat berkonsentrasi, dan untuk memperdulikan rangsangan- 
Philanthrophy Journal of Psychology

Vol 2 Nomor 1 (2018), 27-36

ISSN 2580-6076 (Print), ISSN 2580-8532 (Online)

rangsangan yang tidak penting. Hal ini berkaitan dengan fungsi kognisi yang bekerja tidak sama dengan anak normal (Paternotte dan Buitelaar, 2010).

Fungsi kognisi yang menunjukkan gangguan pemustan perhatian pada anak ADHD terletak pada bagian lobus frontalis. Gangguan tersebut lebih tepatnya pada neurotransmitter catecholamine yakni dopamine dan norepinephrine yang berperan besar dalam atensi, konsentrasi, yang dihubungkan dengan fungsi kognitif misal motivasi, perhatian, dan keberhasilan belajar anak. Dalam norepinephrine dan dopamine ditekankan peran untuk mempertahankan dan memusatkan perhatian (Setyawan, 2015). Anak ADHD tidak dapat mengontrol diri dari stimulus yang ada dari dalam maupun luar dirinya sehingga sulit untuk memusatkan perhatian (Paternotte dan Buitelaar, 2010).

Berdasarkan observasi dan wawancara dalam proses pembelajaran sehari-hari, anak sulit untuk memusatkan perhatian saat guru menjelaskan pembelajaran di dalam kelas. Hal tersebut mengakibatkan anak selalu ditegur oleh guru dan pembelajaran selalu terhenti karena guru meminta anak untuk memperhatikan penjelasan yag disampaikan. Di dalam kelas selain ditegur oleh guru, anak juga ditegur oleh teman-temannya. Hal tersebut dkarenakan anak sering terganggu oleh stimulus lain yang tidak ada hubungan dengan tugas, sehingga sulit memahami perintah tugas serta lama dalam mengerjakan tugas. Jika guru akan membahas tugas yang diberikan teman-teman yang lain harus menunggu anak tersebut sehingga membuat temantemannya marah. Selain itu orangtua mengeluh anaknya sering melupakan tugas atau tertinggal catatan pelajaran sehingga sulit untuk belajar. Orangtua harus meminjam catatan dari anak lain agar anaknya dapat belajar.

Gangguan pemusatan perhatian anak ADHD ini harus segera diatasi. Label yang diberikan oleh orang lain dan juga keyakinan diri anak yang sulit untuk memahami hal yang dijelaskan guru dapat berdampak pada kehidupan sehari-hari. Anak yang mengalami kesulitan memahami perintah dan kesulitan menyesuaikan diri akan menimbulkan permasalahan lain pada saat mereka mengerjakan tugas dari guru. Selain itu dalam setiap tugasnya anak akan mengerjakan banyak kesalahan karena tidak paham mengenai perinah tugas yang diberikan. Salah satu treatment yang dapat diberikan pada anak ADHD yakni pemberian motivasi untuk dapat mengontrol diri melalui perintah pada diri sendiri agar dapat mengatur perilakunya agar sesuai dengan kondisi dan situasi anak tersebut berada. Perintah yang diberikan bagi anak ADHD haruslah jelas dan mudah dipahami. Tujuan dari penelitian ini adalah untuk membantu anak ADHD meningkatkan durasi pemusatan perhatian ketika berada di dalam kelas. 


\section{Metode}

Subyek penelitian adalah anak laki-laki yang telah didiagnosis ADHD, berusia 12 tahun berjumlah 2 orang yang bersekolah di sekolah umum. Sebagai asesmen digunakan WISC, tes Grafis, dan ADHD Rating scale for Children, kamera, dan perekam suara. Hasil asesmen tersebut untuk melihat kecenderungan ADHD. Kamera untuk melakukan observasi durasi pemusatan perhatian. Perekam suara untuk melakukan wawancara terhadap subyek, orangtua dan guru kelas. Penelitian ini menggunakan variabel bebas metode self instruction untuk melatih anak ADHD mengatur diri agar dapat memusatkan perhatian. Self instruction merupakan teknik self talk atau kemampuan berbicara secara pribadi yang digunakan anak untuk membantu regulasi diri dan menuntun perilaku. Metode self instruction menstimulasi pernyataan diri untuk langsung mengatur perilaku diri. Melalui self instruction anak sungguh benar-benar belajar untuk berbicara pada diri sehingga dapat mengontrol diri saat berada di dalam kelas. Metode self instruction merupakan salah satu teknik dari Cognitive behaviour therapy (CBT). CBT adalah treatment yang digunakan untuk mengintervensi pemikiran yang mengalami disfungsi, perilaku maladaptif, dan proses kognitif untuk menentukan goal setting. Konsep dasar CBT adalah manusia akan bertindak persis seperti apa yang dipikirkannya. Metode self instruction yang dikembangkan yang digunakan yaitu:

1. Anak dibimbing untuk berbicara pada diri sendiri mengenai hal yang harus dilakukan.

2. Anak berbicara pada diri sendiri dengan suara keras untuk memberi sinyal kesadaran mengenai apa yang harus dia lakukan untuk memerintah diri sendiri.

3. Anak berlatih berbicara berbisik untuk semakin menginternalisasi perintah diri yang dilakukan. Bicara dalam hati merupakan salah satu kontrol diri agar dapat menggunakan fungsi pengaturan diri.

4. Anak berlatih berbicara dalam hati untuk semakin menginternalisasi perintah pada diri sendiri dan semakin menumbuhkan kesadaran anak bahwa anak dapat memerintah diri sendiri untuk mengatur dirinya sendiri.

5. Penguatan diberikan pada saat evaluasi setelah anak berhasil atau masih memerlukan bimbingan untuk mengatur diri menggunakan metode self instruction.

Variabel tergantung yang digunakan adalah gangguan pemusatan perhatian. Berikut adalah Indikator perilaku pemussatan perhatian yang digunakan.

\begin{tabular}{cll}
\hline Item & $\begin{array}{c}\text { Indikator perilaku } \\
\text { Pemusatan Perhatian }\end{array}$ & \multicolumn{1}{c}{ Definisi Operasional } \\
\hline 1. & Memperhatikan penjelasan guru & $\begin{array}{l}\text { Mata anak tertuju pada guru tanpa } \\
\text { memperhatikan stimulus lain saat guru } \\
\end{array}$ \\
& memberi penjelasan atau perintah \\
\hline
\end{tabular}




\begin{tabular}{|c|c|c|}
\hline 2. & Mengikuti ekspresi wajah guru & $\begin{array}{l}\text { Ikut menanggapi dengan ekspresi wajah } \\
\text { yang sesuai dengan ekspresi guru } \\
\text { (tersenyum, tertawa, takut, senang, } \\
\text { sedih) saat guru memberi penjelasan } \\
\text { melalui cerita. }\end{array}$ \\
\hline 3. & $\begin{array}{l}\text { Mengerjakan tugas sesuai perintah } \\
\text { guru hingga selesai tanpa } \\
\text { meninggalkan tempat duduk. }\end{array}$ & $\begin{array}{l}\text { Duduk tenang mengerjakan soal latihan } \\
\text { yang diberikan guru hingga selesai tanpa } \\
\text { jeda melakukan kegiatan pribadi di luar } \\
\text { kegiatan pembelajaran (berjalan-jalan di } \\
\text { dalam kelas, mengobrol dengan teman } \\
\text { mengenai hal yang tidak ada } \\
\text { hubungannya dengan pelajaran). }\end{array}$ \\
\hline
\end{tabular}

Pengukuran yang dilakukan adalah lama durasi pemusatan perhatian. Setelah itu data dihitung secara kuantitatif. Penghitungan secara kuantitatif yakni dengan menggunakan SPSS, analisis Uji t yaitu Independent Sample Test.

\section{Hasil}

\section{Analisis Uji t}

Secara keseluruhan hasil yang didapatkan untuk $\mathrm{N}=8$ pada kedua subyek didapatkan hasil $t=5,143$ dengan taraf signifikansi $\alpha=0,05$. Pada $\mathrm{df}=14$ dapat dilihat dalam tabel tertera 2 , 145. Secara keseluruhan maka dapat dinyatakan bahwa $t_{0}(5,143)>t_{t a b}(2,145)$. Hasil tersebut dapat diartikan bahwa secara signifikan ada perbedaan durasi lamanya pemusatan perhatian pada anak ADHD setelah mendapat treatment dengan metode self instruction. Hasil analisis ini sesuai dengan hipotesis yang diajukan, yakni self instruction dapat meningkatkan pemusatan perhatian pada anak ADHD. 
Philanthrophy Journal of Psychology

Vol 2 Nomor 1 (2018), 27-36

ISSN 2580-6076 (Print), ISSN 2580-8532 (Online)

\section{Gambar Grafik Subyek E}

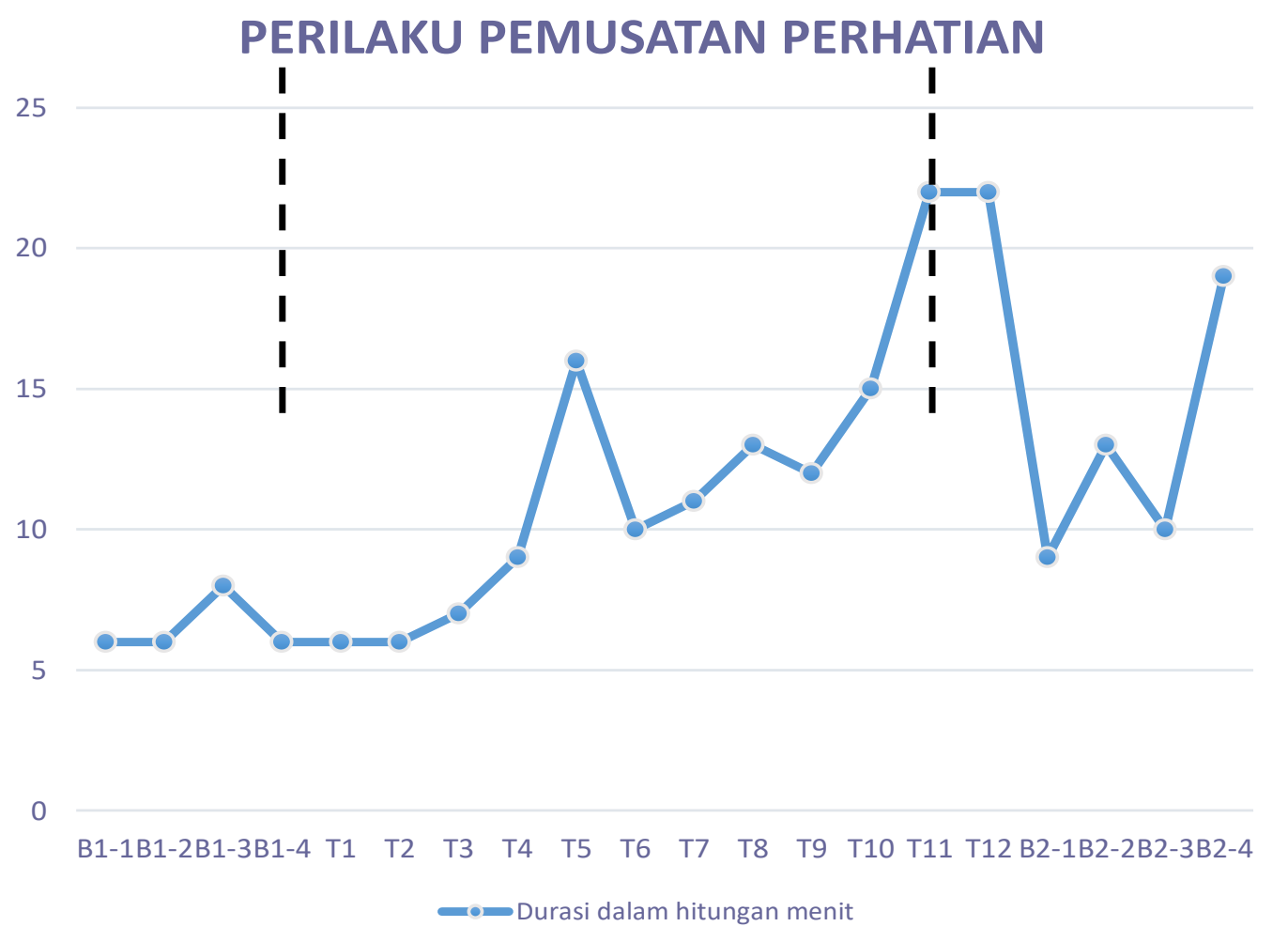

\section{Gambar Grafik Subyek S}

\section{Perilaku Pemusatan Perhatian}

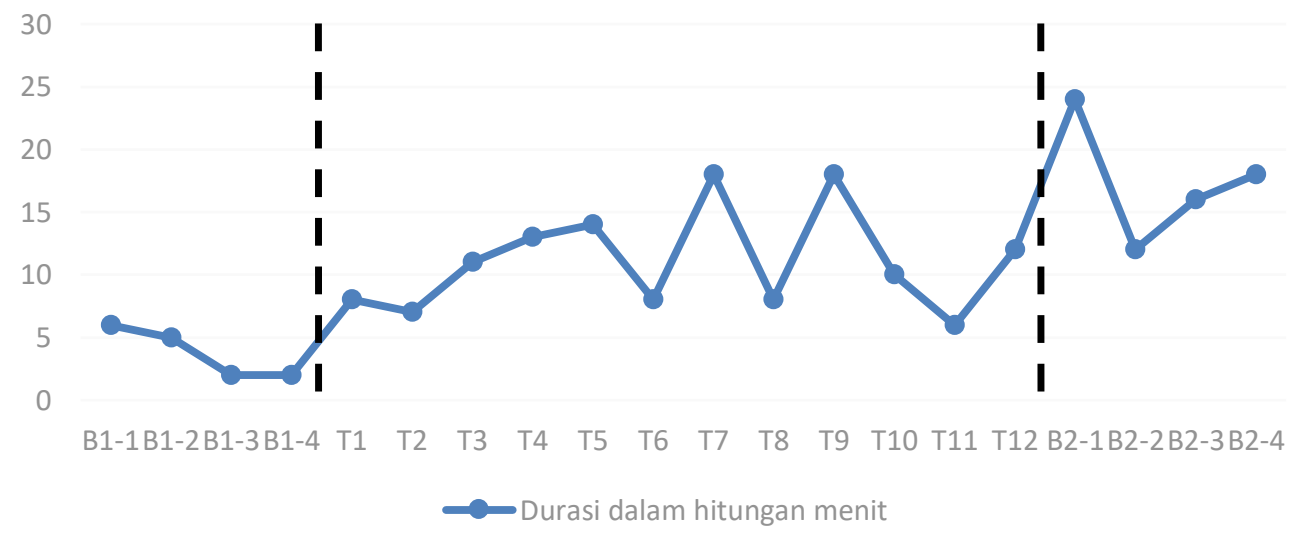




\section{Diskusi}

Hasil analisis penelitian menunjukkan bahwa hipotesis dapat diterima. Berdasarkan analisis uji statistik dan grafik ditunjukkan bahwa kedua subyek mengalami peningkatan durasi pemusatan perhatian. Hasil durasi pemusatan perhatian yang ditunjukkan selama treatment menunjukkan hasil yang mengalami peningkatan. Subyek penelitian merupakan siswa Sekolah Menengah Pertama yang berusia 12 tahun. Subyek penelitian adalah anak ADHD dengan tingkat hiperaktivitas sedang sehingga sudah dapat diajak untuk berdiskusi dan diberi pengarahan. Inisial subyek adalah subyek E dan subyek S.

Subyek E dan subyek S mengalami kenaikan durasi pemusatan perhatian di setiap harinya. Kenaikan durasi pemusatan perhatian subyek E dari durasi terendah 6 menit sebelum mendapat treatment dan durasi terlama 19 menit setelah mendapat treatment. Kenaikan durasi subyek S dari durasi terendah 2 menit sebelum mendapat treatment menjadi 24 menit durasi terlama setelah mendapat treatment. Durasi tersebut diambil berdasarkan hitungan selama 40 menit.

Pada saat masa treatment kedua subyek sempat mengami penurunan durasi pemusatan perhatian. Penurunan durasi pemusatan perhatian tersebut disebabkan karena subyek S sedang sakit namun masih mengikuti pembelajaran di dalam kelas. Subyek E masih harus mendapat pelatihan lebih untuk melakukan metode self instruction untuk mengontrol diri. Berdasarkan hasil wawancara dengan guru kelas didapatkan bahwa subyek E dan subyek $\mathrm{S}$ menunjukkan peningkatan dalam memusatkan perhatian.

Langkah awal sebelum melakukan metode self instruction subyek E dan subyek S secara pribadi berada dalam ruangan bersama peneliti. Peneliti melakukan pendekatan dengan memberi pertanyaan kepada subyek sebagai berikut:

1. Apa yang biasa kamu lakukan di dalam kelas?

2. Apa yang membuat tugas sekolah mu sering tidak selesai?

Subyek E memberikan jawaban bahwa dirinya tidak memahami tugas yang diberikan guru. Subyek E seringkali bertanya tugas yang diberikan dan apakah pekerjaannya sudah betul atau belum. subyek merasa dirinya tidak seperti teman-teman yang lain yang langsung bisa mengerjakan tugas. Subyek S hanya mengatakan jika tidak bisa. Saat ditanya oleh peneliti mengapa tidak bisa jawabannya hanya tidak tahu. Hal ini sesuai dengan pernyataan bahwa fungsi kognisi anak ADHD berbeda dengan anak normal seusianya. Saat anak lain dapat memusatkan perhatian dan 
memahami perintah yang diberikan, anak ADHD lebih mudah terdistraksi oleh stimulus lain yang tidak berhubungan dengan proses pembelajaran di dalam kelas (Setyawan, 2015).

Setelah peneliti mengajak subyek untuk mendalami pemikiran subyek, peneliti kemudian memberi motivasi pada subyek bahwa mereka bisa menyelesaikan tugas sekolah jika mereka dapat memperhatikan penjelasan guru hingga selesai. Peneliti memberi motivasi pada kedua subyek bahwa mereka bisa memperhatikan penjelasan guru hingga selesai. Setelah memberi motivasi dan mengubah pola pikir kedua subyek menjadi pemikiran yang positif, terapis lalu mengajarkan cara melakukan metode self instruction untuk mengontrol perilaku untuk memusatkan perhatian memperhatikan penjelasan guru dalam kelas. Kata yang diinstruksikan untuk mengontrol perilaku subyek adalah "aku harus memperhatikan guru".

Metode self instruction diterapkan oleh subyek E dan S sebelum memulai pembelajaran di setiap mata pelajaran. Metode tersebut dilakukan masih dalam serangkaian treatment dan berhenti saat treatment selesai. Situasi di dalam kelas merupakan sensor bagi subyek E dan S sehingga memori mereka langsung bekerja untuk me-recall ingatan yakni untuk memerintah diri sendiri untuk mengontrol diri saat mendengar penjelasan guru dan mengerjakan tugas dari guru. Perilaku pemusatan perhatian yang muncul karena kontrol diri tersebut tampak pada peningkatan durasi pemusatan perhatian subyek $\mathrm{E}$ dan $\mathrm{S}$.

Saat mengikuti sesi terapi berikutnya subyek E dan S selalu dievalusi mengenai perasaan mereka saat mereka dapat mengontrol diri memperjhatikan penjelasan guru. Subyek E menjawab bahwa dirinya sekarang sudah mulai memahami perintah tugas yang diberikan oleh guru. Subyek E merasa senang karena sudah dapat mengontrol diri sehingga dapat meningkatkan kemampuannya untuk memperhatikan penjelasan guru hingga selesai. Subyek S mengatakan bahwa dirinya sudah dapat mendengarkan penjelasan guru dan menjawab pertanyaan dari guru.

\section{Kesimpulan}

Pada hasil penghitungan dapat dilihat hasil hipotesis yang didapat. Hipotesis yang didapat adalah metode self instruction dapat meningkatkan pemusatan perhatian pada anak ADHD. Hasil ini ditunjukkan dalam peningkatan durasi pemusatan perhatian subyek E dan S. Subyek E dan S mengalami peningkatan pemusatan perhatian dalam rentang waktu 40 menit. Subyek E megalami kenaikan durasi selama 13 menit sedangkan subyek S mengalami kenaikan selama 22 menit. 
Performansi subyek E dan subyek $\mathrm{S}$ dalam proses pembelajaran juga semakin meningkat. Subyek E sudah dapat memahami perintah tugas yang diberikan. Subyek S sudah dapat menjawab pertanyaan guru. Efek yang didapatkan dari melakukan kontrol diri untuk mendengarkan penjelasan guru sudah dapat didapatkan oleh kedua subyek sehingga menambah motivasi subyek untuk mengontrol diri untuk mendengarkan penjelasan guru dan mengabaikan stimulus lain yang tidak berhubungan dengan proses pembelajran di dalam kelas.

\section{Kepustakaan}

Alwisol. 2005. Psikologi Kepribadian Edisi Revisi. Al.ih bahasa: M. Achyar Muslimin. Malang: Universitas Muhammadiyah Malang

American Psychiatric Association. 2012-2013. Diagnostic And Statistical Manual Of Mental Disorders Fifth Edition. Washington, DC; London, England : American Psychiatric Publishing

Ayres, J. A. 2005. Sensory Integration And The Child _ Understanding Hidden Sensory Challenges. Amerika : wps

Azwar, S. 1997. Reliabilitas Dan Validitas. Yogyakarta: Pustaka Pelajar

Berger, A; Kofman, 0; Livneh, U; Henik, A. 2007. Multidisciplinary Perspectives On Attention and The Development Of Self-Regulation. Journal Progres in Neurobiology 82 (2007) 256-286. Israel: Departement of Psychology and Zlotowski Center for Neuroscience, Ben-Gurion University of Negev

Cully, J; Teten, A. 2008. A Therapist's Guide To Brief Cognitive Behavioral Therapy. Houston: Department of Veterans Affairs South Central MIRECC

Fuster, J.M. 2002. Frontal Lobe and Cognitive Development. Journal of Neurocytology. Neuropshychiatric and Brand Research Institute, UCLA School of Medicine Los Angeles, California joaquinf@ucla.edu

Flores, G; Parra, V. 2014. Cognitive Behavioral Treatment in Children with Attention Deficit Hyperactivity Disorder. Revista de Psicologia: Universidad de Antioquia. Journal Vol.6 No.2

Haris, C.M; Graham, P. 2006. Cognitive Behaviour Therapy For Children And Families_Second Edition. London : Cambridge University

Howell, D.C. 1982. Statistical Methods for Psychology. Boston: Duxbury Press

Lange, A, Rene. R, Aagje. G, Marjan. V, Litanja. L. 1998. The Effects

Of Positive self instruction: A Controlled Trial. Cognitive Therapy Research. Journal Vol.22, No.03, pp.225-236

Mash. J, E and Barkley, RA. 2003. Child Psychopathology_Second Edition.

New York : The Guilford Press

Paternotte, A; Buitelaar, J. 2010. Attention Deficit Hyperactivity Disorder. Alih bahasa: Julia Maria van Tiel. Jakarta : Prenada

Pessoa, L; Sabine, K; Leslie U. 2003. Journal_Neuroimaging Studies Of Attention : From Modulation Of Sensory Processing To Top -Down Control. New Jersey : The Journal Of Neuroscience

Putranto, K.A. 2008. Metamorfosis. Jakarta : Penerbit Kreatif Media Indonesia 
Raz, A. 2004. Anatomy of Attentional Networks. Journal The Anatomical Record (Part B :New Anat) 281B:21-36

Reid, R. 2006. Self-Regulated Strategy Development for Written Expression With Students With Attention Deficit/Hyperactivity Disorder. Journal Vol.73. No 1, pp. 53-68. Lincoln : University of Nebraska

Robert, S.A. 2011. Psikologi Pendidikan Teori dan Praktik. Jakarta : PT. Indeks

Setyawan, AB. 2015. Aspek Neurologis : Attention Deficit Hiperactivity

Disorder (ADHD). Surabaya: Fakultas Kedokteran

Universitas Wijaya Kusuma Bagian Psikiatri

Schacter, C.E; Millman H.L .1981. How To Help Children With Common Problems. America :Van Nostrand Reinhold Company. Inc

Thyagarajan. 2016. A Case Study Using Cognitive- Behavioral Therapy- Management of ADHD. The International Journal of Indian Psychology. ISSN 2348-5396 (e) I ISSN: 2349- 3429 (p). Volume 3, Issue 3, No.8, DIP : 18.01.140/20160303. ISBN: 978-1-365-12176-0. http://www. ijip.in Villar, 0.2007. Cognitive Treatmen For Children With Attention Deficit Hiperactivity Disorder (ADHD). Review and New Contributions. Spanish : Departement of Developmental Psychology and Education Spanish University for Distance Learning 